\title{
RATE OF IMPAIRED GLUCOSE REGULATION IN OUTPATIENT CARE
}

\author{
Lina Zabuliene ${ }^{1,2}$, Birute Pauliukiene ${ }^{2}$, Jurgita Urboniene ${ }^{3}$ \\ ${ }^{1}$ Clinics of Rheumatology, Traumatology-Orthopaedics and Reconstructive Surgery, Faculty of Medicine, Vilnius University, \\ Vilnius, Lithuania; \\ 2 Antakalnio outpatient clinic, Vilnius, Lithuania \\ 3 Infectious Diseases and Tuberculosis Hospital, Vilnius University hospital Santariskiu klinikos, Vilnius, Lithuania
}

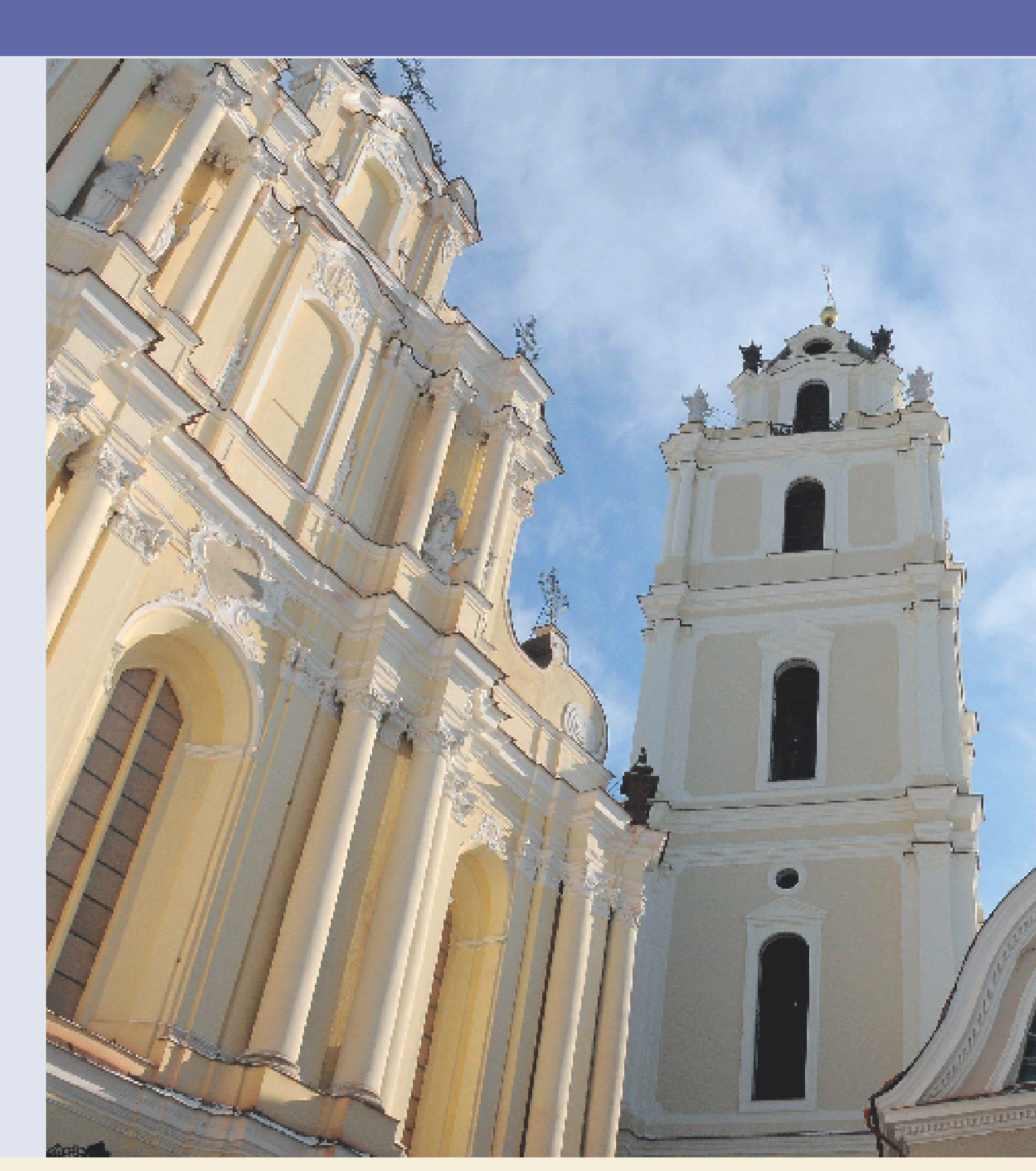

\section{INTRODUCTION:}

Increasing incidence of type 2 diabetes remains unsolved public health problem all over the world [1]. Insufficient diabetes control and long term complications threaten health and quality of life of suffered persons and have impact on global economies [2]. Many of individuals with type 2 diabetes remain unidentified for many years because of its silent course [3]. Rate of undiagnosed diabetes varies in different regions reaching up to $83.8 \%$ in the Pacific Islands [4]. Screening for diabetes within general practice by measuring fasting blood glucose or performing oral glucose tolerance test is the main measure of diabetes secondary prevention. The individuals with multiple risk factors for diabetes should be targeted for these measures [3, 5-8].

\section{OBJECTIVE:}

The objective was to assess the rate of impaired glucose regulation and progression to diabetes in adults using routinely collected health care data.

\section{MATERIAL AND METHODS:}

We conducted an audit on results of 75-g standardized oral glucose tolerance test (OGTT) performed at Vilnius city Antakalnio outpatient clinic from 03 Jan 2011 to 15 Dec 2014 and analysed data of 5933 adult patients, who were at risk for development of diabetes. All anonymous data were obtained from electronic records of routine clinical care. We excluded from analysis data of 358 patients who didn't perform a 2 hours post load plasma glucose concentration ( $2 \mathrm{hPG}$ ) test. 5575 patients' data were included into the final analysis. We applied the 2006 World Health Organization criteria for diabetes, impaired glucose tolerance (IGT) and impaired fasting glucose (IFG) [9].

We used SPSS version 20.0 for statistical analyses. The Shapiro-Wilk test was used to examine for normal distribution. Student's t-test and ANOVA was used to compare the means for independent samples. Apvalueof $<0.05$ wasconsidered as significant.

\section{RESULTS:}

Mean patients' age was $53.64 \pm 15.59$ years. The youngest patient was 18 years old and the oldest was 93 .

$36.4 \%$ of the patients were men and $63.6 \%$ were women. Mean fasting plasma glucose (FPG) concentration was

$5.87 \pm 0.65 \mathrm{mmol} / \mathrm{l}$, mean 2 hours post load plasma glucose ( $2 \mathrm{hPG}$ ) concentration was $6.20 \pm 2.25 \mathrm{mmol} / \mathrm{l}$. FPG in women was significantly lower than in men, but $2 \mathrm{hPG}$ was significantly higher in women than in men (Table 1).

Table 1. Patients' characteristics

\begin{tabular}{|l|c|c|c|c|}
\hline \multicolumn{1}{|c|}{ Variable } & $\begin{array}{c}\text { Study population, } \\
\mathbf{N = 5 5 7 5}\end{array}$ & $\begin{array}{c}\text { Men, } \\
\mathbf{N = 2 0 2 8}\end{array}$ & $\begin{array}{c}\text { Women, } \\
\mathbf{N = 3 5 4 7}\end{array}$ & $\begin{array}{c}\text { p, } \\
\text { comparing men and women }\end{array}$ \\
\hline Age, years & $53.64 \pm 15.59$ & $52.98 \pm 14.57$ & $54.01 \pm 16.14$ & 0.014 \\
\hline Fasting plasma glucose, $\mathrm{mmol} / \mathrm{l}$ & $5.87 \pm 0.65$ & $6.03 \pm 0.60$ & $5.79 \pm 0.67$ & $<0.0001$ \\
\hline 2 hours post load plasma glucose, $\mathrm{mmol} / \mathrm{l}$ & $6.20 \pm 2.25$ & $6.09 \pm 2.44$ & $6.25 \pm 2.14$ & 0.011 \\
\hline
\end{tabular}

We found that the mean $2 \mathrm{hPG}$ concentration increased with age, but the FPG concentration remained unchanged starting from 40-49 years (Fig. 1).

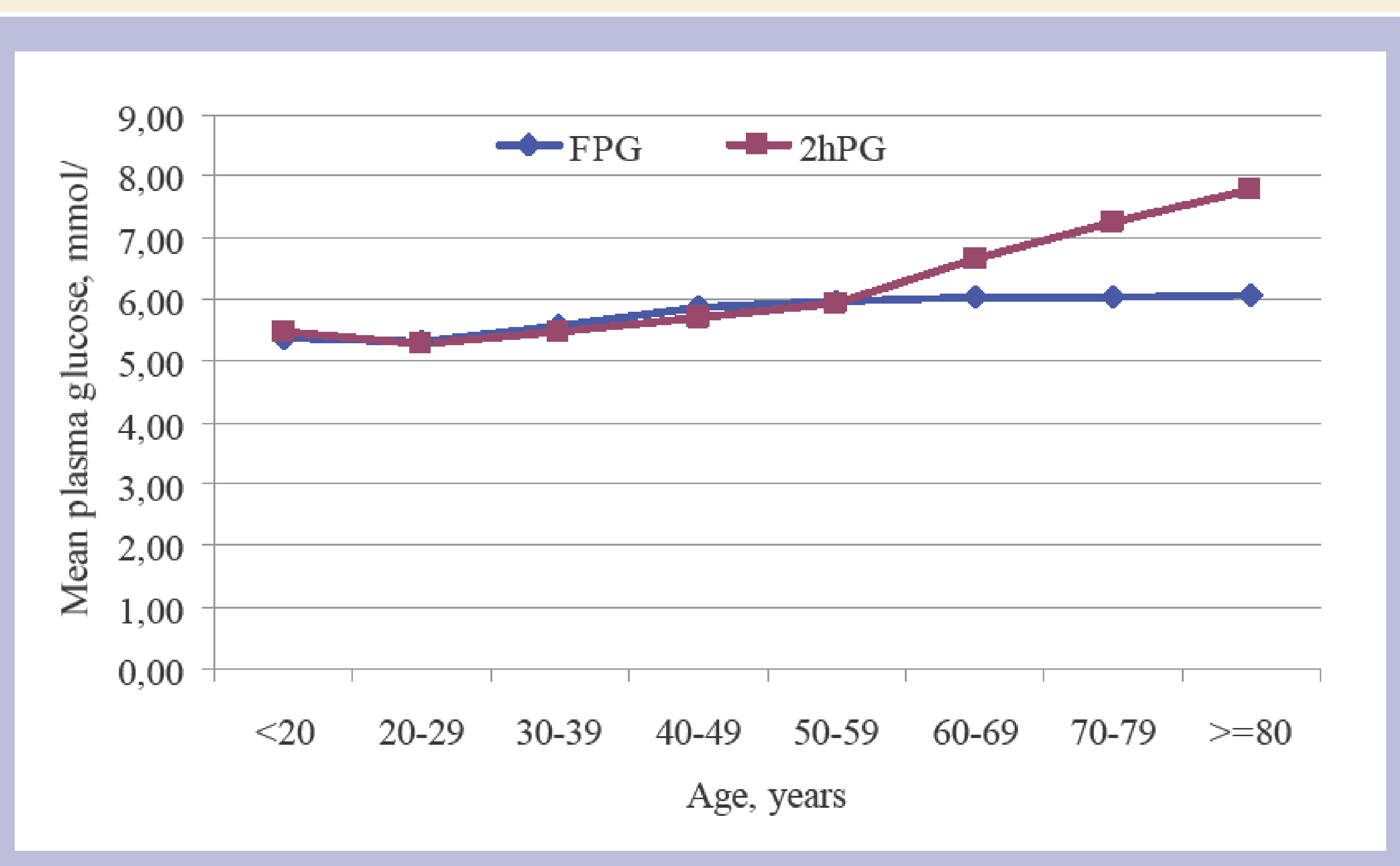

Fig. 1. Mean fasting plasma glucose and 2 hours post load plasma glucose in different age groups.

The rate of IGT steadily increased with age. The rate of diabetes dropped in group aged 20-29 years comparing with younger group, but starting from the group of age of 30-39 years diabetes rate steadily increased. IFG increased with age achieving peak in groups of 50-59 years and 60-69 years old patients (Fig. 3).

787 patients repeated OGTT second time, which revealed 48 new cases of diabetes. Before developing diabetes $58.3 \%$ patients had IGT, $22.9 \%$ had IFG, and $18.8 \%$ had normal glucose tolerance. Mean time from the first OGTT to diabetes development was $18.15 \pm 9.36$ months. Female gender $(\mathrm{OR}=2.42$, $\mathrm{p}=0.028)$ and IGT $(\mathrm{OR}=6.08, \mathrm{p}<0.001)$ predicted diabetes.

\section{CONCLUSION}

This analysis revealed that the rate of undiagnosed diabetes is $5.1 \%$; nearly half of outpatient patients with risk factors for diabetes have impaired glucose regulation. Women with history of impaired glucose tolerance have higher risk for diabetes development.

\section{REFERENCES}

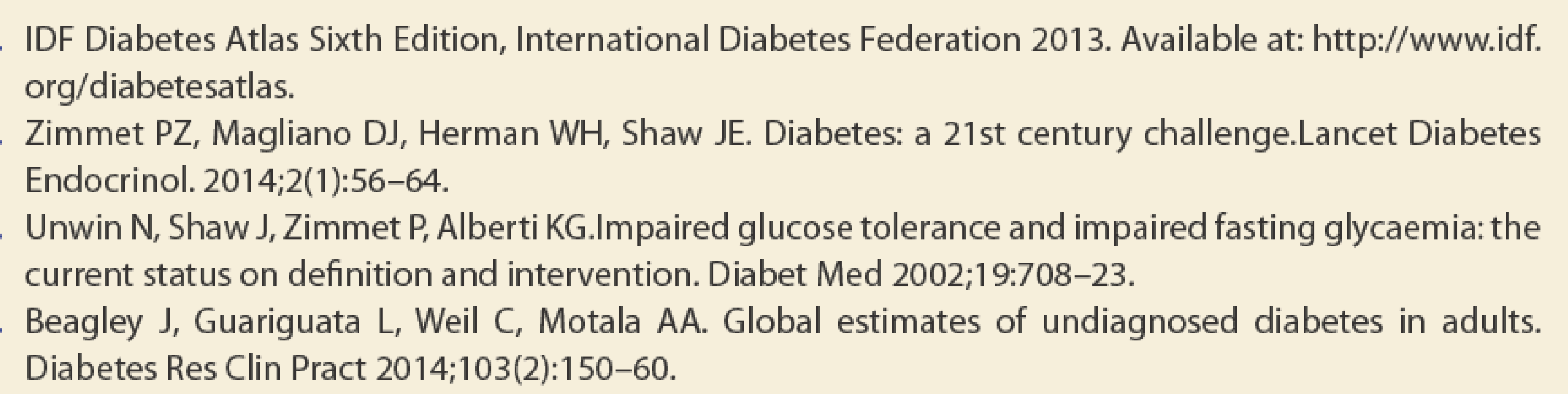

5. Diabetes Prevention Research Group. Reduction in the incidence of type 2 diabetes with lifestyle intervention or metformin. N Engl J Med 2002;346:393-403.

to ez-Jaramillo P,Velandia-Carrillo C, Gomez-Arbelaez D, Aldana-Campos M. Is the present cut-point American Diabetes Association. Diagnosis and classification of diabetes mellitus. Diabetes Care 2014;37(Suppl. 1):581-S90.

American Diabetes Association. Standards of medical care in diabetes-2015: summary of revisions. Diabetes Care 2015;38 Suppl:54.

World Health Organization. Definition and diagnosis of diabetes mellitus and intermediate hyperglycemia. Report of a WHO/IDF consultation; 2006 